\title{
EFFECT OF PAPER SURFACE PROPERTIES ON INK COLOR CHANGE, PRINT GLOSS AND LIGHT FASTNESS RESISTANCE
}

\author{
CEM AYDEMIR, ${ }^{*}$ NEMANJA KAŠIKOVIĆ, ${ }^{* *}$ CSABA HORVATH ${ }^{* * *}$ and \\ STEFAN DURDEVIC ${ }^{* *}$ \\ "Marmara University, School of Applied Science, \\ Department of Printing Technologies, Istanbul, Turkey \\ ** University of Novi Sad, Department of Graphic Engineering and Design, Novi Sad, Serbia \\ *** Óbuda University, Institute of Media Technology and Light Industry Engineering, \\ Budapest, Hungary \\ $₫$ Corresponding author: Cem Aydemir, cemaydemir@marmara.edu.tr
}

Received August 6, 2020

Printability is a combination of paper-related factors that contribute to achieving the desired print quality level and relates to the paper's ability to absorb ink. An important property of ink on paper is its setting behavior. The spread and placement of the ink on the paper surface is affected by the surface structure of the paper. The surface topography of the paper is decisive in the process of ink placement on the paper surface.

In this study, the effects of surface roughness of the paper on wettability, print gloss, ink color change and light fastness change were investigated. For this purpose, prints on papers with different surface roughness were made in accordance with ISO 12647-2 with Cyan color ink in accordance with DIN ISO 2846-1. The CIE $L^{*} a^{*} b^{*}$ and gloss values of the test prints, which were allowed to dry in order to detect color and print gloss differences on the paper surfaces, were measured periodically until the ink film was completely dry. In addition, the effects of the paper surface on the light fastness of the ink were measured and recorded. The results were discussed in terms of print quality.

Keywords: paper, surface roughness, contact angle, surface energy, printability

\section{INTRODUCTION}

Paper is a composite structure in layers with different porosity, obtained by random arrangement of cellulose fibers. ${ }^{1}$ This variable porous composite structure is extremely important for both liquids and gases. ${ }^{2,3}$ The visual quality of the print result in printing systems largely depends on a physico-chemical interaction between paper and ink, especially the process of ink setting and drying on the printing substrate. ${ }^{4,5}$ In the process of fluid ink settling and absorption onto the paper surface, the surface characteristics of the paper are extremely important. Therefore, the surface structure of the paper is the most effective parameter for achieving print quality. ${ }^{6,7}$

The most important surface feature of the paper is surface smoothness or roughness. The distribution of the fibers on the screen during the paper production, the short-long fiber structure, the amount of filler and the calendering degree determine the surface smoothness or roughness of the paper. Surface roughness is a measure of the degree of deviation of the paper surface from a flat surface and characterizes the indentation and topography of the paper surface. From the topography of the paper, the geometric structure of the paper surface is understood. As the profile rises and falls, the paper becomes coarser. This determines the visual effect, texture, and printability of the paper. ${ }^{8}$ Printability is the main parameter for high quality colour reproduction, increased ink gloss, uniform appearance or preventing print defects. ${ }^{9}$ Depth and width differences on the paper surface can affect the quality parameters of the ink film, such as ink settling on the paper, print density, print gloss, and color CIE $L * a * b *{ }^{10}$

One of the most important reasons for controlling and measuring the surface smoothness is print quality. In contact printing processes, the ink film is transferred to the paper surface by physical contact. When the pores on the paper surface are deep enough to prevent contact, the 
ink cannot be transferred to these low areas and uneven ink transfer will result in poor print quality.

A measurement of the ink film thickness is done with its optical density. The ability of an ink to spread laterally across the sheet has a significant effect on print density. The change in print density is an important parameter that determines the color and gloss of the ink film. As surface smoothness increases, the ink requirement and print density for sufficient coating decreases. When the ink film is adjusted to provide satisfactory print density on rough areas of the paper, this time the same ink thickness may be too high for optimum print quality on the smooth areas of the paper. This can cause mottling and other printing problems. ${ }^{11}$

The degree of ink film settling on the paper surface is also important in printing due to the contrast created between the ink and the paper. If the ink is on paper, it absorbs light effectively. The more ink settling on the paper, the less ink that will absorb light remains on the surface. Thus, the ink loses its gloss and is perceived as different in color. The same ink film printed on paper with different surface properties appears as having different colors.

The resistance of the ink film to light is known to depend on the exposure of the ink to the light, as well as the thickness, transparency, pigmentation, high filler or white pigment content factors of the ink film. However, studies on the effect of the printing substrate on ink film light fastness are limited.

The main purpose of the present study is to determine the effects of paper surface roughness on the print quality parameters. For this purpose, first of all, water contact angles in papers with different surface roughness were measured and surface energies were calculated. Then, offset printing was performed on these controlled papers in accordance with Standards 12647-2 in the laboratory. By applying colorimetric measurements on printed samples, the effects of surface roughness of the paper on ink color change, print gloss and ink light fastness were examined and discussed.

\section{EXPERIMENTAL}

\section{Materials and methods}

In the study, firstly, surface roughness and water contact angle parameters, which determine the surface properties of papers with different surface structures, were measured; surface energy values were calculated and recorded. These papers with different surface characterization were tested in the laboratory environment with Sun Chemical SunLit Express Offset Cyan ink, which meets DIN ISO 2846-1 standards. Standard printing room conditions were maintained during the printing process. The color change (ISO 12647-2:2013), print gloss (ISO 2813:2014) and resistance to light (British Standards (BS) 4321) parameters of the ink film, which determine the quality of printing, were measured and recorded.

\section{Characterization of paper surface}

The structure and surface energy of the paper greatly affect its interaction with liquids. ${ }^{12}$ Since surface roughness affects the surface energy of the paper, it causes differences in capillary absorption. ${ }^{13-15}$ Thus, the absorption rate of the liquid by the paper and the spread on the surface is affected in different directions. ${ }^{12}$ The surface energy of paper is commonly determined by liquid contact angle measurement. ${ }^{16}$ The contact angle measured at the base of the droplet describes the relationship between the surface tension of the liquid and the surface free energy of a solid surface. ${ }^{17}$

In the study, $80 \mathrm{~g} / \mathrm{m}^{2}$ uncoated papers with different surface roughness were used as print substrate. The roughness of the papers was measured using the Bentsen method, with a Lorentzen \& Wettre Roughness Tester, applying constant compressed air (98 $\mathrm{kPa})$, as specified in the SCAN-P 21 TAPPI UM 535 standard test method.

In order to determine the effect of the surface roughness of papers on their surface energies, water contact angle measurements were made using the sessile drop technique (Fig. 1). A PGX Pocket Goniometer (FIBRO System AB), with program version 3.4, was used for the measurements, in accordance with the Tappi T458 standard test method. The measurements were carried out in a closed system and were recorded with a CCD camera.

The surface energies of the papers were calculated according to the ASTM D5946 standard test method, ${ }^{18}$ depending on the water contact angle values. The relationship between a static contact angle and the surface energy forces was defined by Young from the interfacial tensions (Eq. (1)):

$\gamma_{S V}=\gamma_{S L}+\gamma_{L V} \cos \theta$

where $\gamma_{S V}=$ solid-vapour interaction; $\gamma_{S L}=$ solidliquid interaction; $\gamma_{L V}=$ liquid-vapour interaction (Fig. 2).

The surface roughness, contact angle and surface energy values of the papers with the same weight but different surface structures are given in Table 1.

Surface energy is extremely important as it directly affects how well the ink wets the substrate surface. In general, a surface with low surface energy causes poor wetting. The study showed that as the test papers' surface roughness increased, the liquid contact angle 
increased and the surface energy decreased. This demonstrates that, similarly to polymer films, better wettability can be achieved in printing papers with higher surface energy and low roughness.

\section{Ink transfer onto paper substrates}

The papers with specified surface properties were conditioned for 24 hours at $23 \pm 1{ }^{\circ} \mathrm{C}$ temperature and $50 \% \pm 3 \%$ relative humidity, in accordance with the DIN EN 20187 standard, in the printing environment before the test prints were made. Test prints were made with the IGT-C1 printability tester at $350 \mathrm{~N} / \mathrm{m}^{2}$ printing pressure and $0.3 \mathrm{~m} / \mathrm{s}$ printing speed, in accordance with the ISO 12647-2: 2013 standard under optimum printing room conditions $(35 \mathrm{~mm}$ printing width). In the test prints made under controlled conditions, mineral oil based uniform cyan color sheetfed offset ink was used in accordance with DIN ISO 2846-1 standards. Standard printing conditions have been maintained in colorimetric measurements after printing. On average 20 replicates were made per test and the results of these 20 test print samples were then averaged.
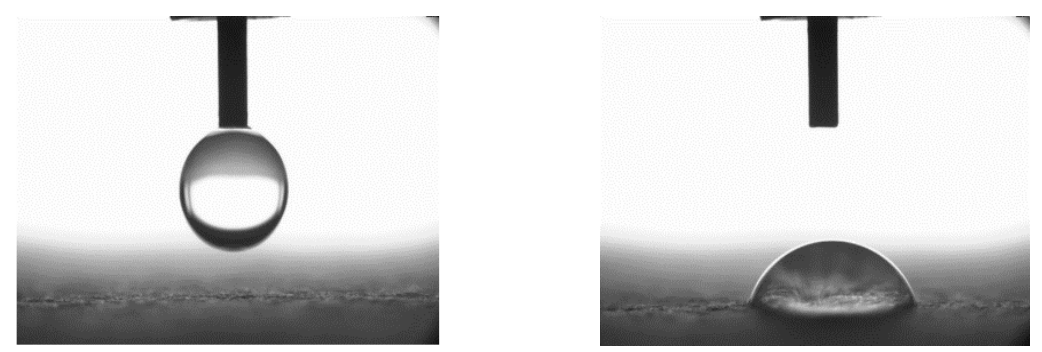

Figure 1: Sessile drop technique

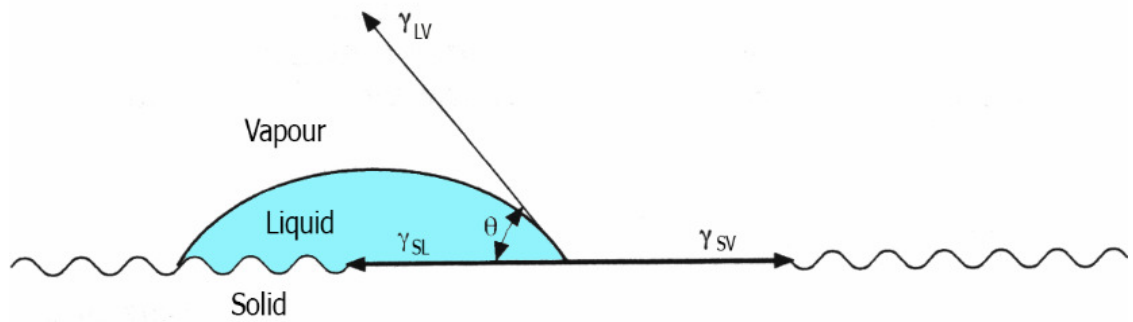

Figure 2: Contact angle of a liquid on a solid surface

Table 1

Properties of uncoated papers used in test prints

\begin{tabular}{lcccc}
\hline Paper & $\begin{array}{c}\text { Surface roughness } \\
\text { Bendtsen (mL/min) } \\
\text { ISO 8791-2 }\end{array}$ & $\begin{array}{c}\text { Water contact } \\
\text { angle (degree) } \\
\text { Tappi T458 }\end{array}$ & $\begin{array}{c}\text { Surface energy } \\
\left(\mathrm{mJ} / \mathrm{m}^{2}\right) \\
\text { ASTM D 5946 }\end{array}$ & $\begin{array}{c}\text { Weight } \\
\left(\mathrm{g} / \mathrm{m}^{2}\right) \\
\text { ISO 536 }\end{array}$ \\
\hline Series 1 & 95 & 79 & 39.8 & 80 \\
Series 2 & 120 & 83.2 & 38.1 & 80 \\
Series 3 & 250 & 93.7 & 36.9 & 80 \\
Series 4 & 260 & 95.9 & 31.4 & 80 \\
\hline
\end{tabular}

\section{Colorimetric analysis}

The CIELAB was set up as a three-dimensional color universe that creates a rectangular or Cartesian coordinate space with the $L^{*}, a^{*}$ and $b^{*}$ axes (Fig. 3). The $L^{*}$ axis denotes brightness, while the $a^{*}$ and $b^{*}$ axes represent the red-green and yellow-blue contrasting colors, respectively. ${ }^{20}$ The color difference is the distance measurement between the two colors in the color space. ${ }^{21}$ The change in the printed ink color over time is expressed as color difference $\left(\Delta E^{*}{ }_{a b}\right)$. The difference between the two colors can be calculated by placing the color coordinates in the three-dimensional CIE $L * a * b *$ color space. $^{22,23}$

In this study, CIE $L^{*} a * b *$ (CIELAB) color measurements of the test samples were carried out with an X-Rite eXact TM Spectrophotometer. Colorimetric measurements were repeated at certain time intervals until the ink film on the paper surface was completely dry (10 days).

The measurements were carried out under M1 
measurement conditions $(400-700 \mathrm{~nm}$ range D50 illuminator, $2^{\circ}$ observer, 0/45 geometry, backrest and polarization filter on) in accordance with the ISO 12647-2:2013 standard. Color differences were calculated in accordance with $\mathrm{CIE} \Delta E^{*}{ }_{a b} 1976$ ISO
13655 standard, depending on time. The print gloss measurements of the test samples were carried out at the $60^{\circ}$ measurement angle with a BYK-Gardner Glossmeter (Geretsried, Germany) at the moment of printing.

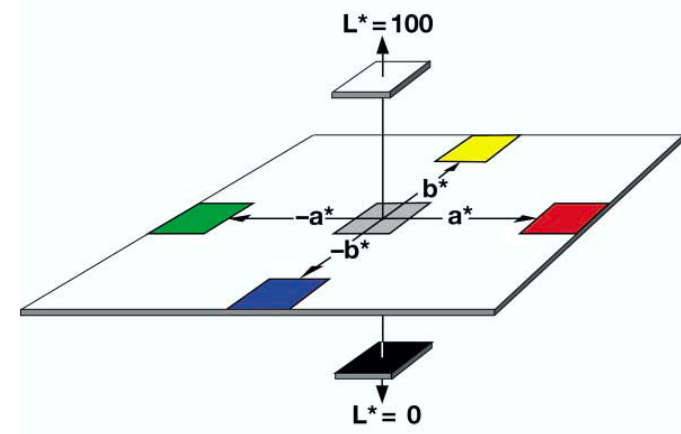

Figure 3: Schematic diagram of Color CIE $L^{*} a * b *$ axes

In order to determine the fading effect of the printing substrate on the printed ink film, samples printed with standard ink under standard printing conditions were exposed to 192 hours of fading in a Solarbox 1500 KFG-2400 Xenon Arc Light Fastness Tester. Color CIE $L^{*} a * b^{*}$ measurements were made before and after fading with the X-Rite eXact Spectrophotometer, and the color differences $\left(\Delta E^{*}\right)$ in the samples were calculated.

\section{RESULTS AND DISCUSSION}

Paper roughness of is a very important feature for print quality. ${ }^{24}$ The effect of surface roughness of papers on the print quality was evaluated according to the color change, print gloss and light fastness criteria in the printed ink film.

\section{Effect of paper surface on print color change}

The differences of color $L^{*} a^{*} b^{*}$ values measured in different time periods, compared to the printing moment color, were calculated using CIELAB based CIE 1976 color-difference formula (Eq. (2)):

$$
\Delta E_{a b}^{*}=\sqrt{\left(L_{2}^{*}-L_{1}^{*}\right)^{2}+\left(a_{2}^{*}-a_{1}^{*}\right)^{2}+\left(b_{2}^{*}-b_{1}^{*}\right)^{2}}
$$

where $\Delta L^{*}, \Delta a^{*}, \Delta b^{*}$ : difference in $L^{*}, a^{*}$, and $b^{*}$ values between the specimen color and the target color. Color difference (Delta E) results are given in Figure 4.

Taking the printing moment color CIE $L^{*} a^{*} b^{*}$ value as reference, it has been observed that the ink film color differences $\left(\Delta E^{*}{ }_{a b}\right)$ that increase over time depend on the decreasing surface smoothness and surface energy of the paper. The ink color printed on papers with high surface energy (smooth surface) changed less than the ink color printed on papers with low surface energy (rough surface). This shows that the surface properties of the paper play a significant role to in ink film color change.

\section{Effect of paper surface on print gloss}

Print gloss is one of the most important features of the printed ink film. The relationship between print gloss and the surface properties of the paper is extremely important in terms of print quality. Gloss is a measure of light reflection and is largely affected by paper smoothness. ${ }^{26}$ If ink is on paper, it absorbs light effectively. The more ink settling on the paper, the less ink that will absorb light remains on the surface. The rough and macroporous structure of the paper surface causes the printed ink to spread and settle on the surface of the paper. Thus, the ink loses its gloss and the color is perceived differently. In this study, the printing gloss measurements of the ink films printed on paper surfaces with different roughness were performed with a BYK Gardner Glossmeter (Sheen Instrument, U.K.), at a $60^{\circ}$ measurement angle.

The test prints indicated that the ink film gloss decreased with the increase of surface roughness of the paper (Fig. 5). The highest printing gloss was obtained on papers with the highest surface smoothness and surface energy. Based on these results, it can be said that the surface roughness of 
the paper and the surface energy have an important effect on the print gloss.

\section{Effect of paper surface on ink light fastness}

Apart from their printing and finishing characteristics, inks often have to meet different requirements. Such requirements mainly concern light fastness and resistance to chemicals. Light fastness refers to the resistance of a color to fading under the sunlight. ${ }^{27}$ Light causes the color to become weak or its tone to change.

The science of light fastness includes standards that have been established to consistently evaluate light fastness, as well as the laboratory analysis of light fastness, which includes using accelerated light fastness testing and the subsequent evaluation. ${ }^{28}$

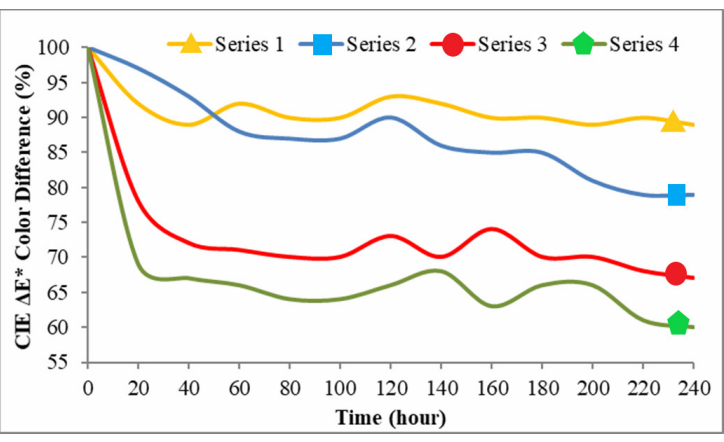

Figure 4: Ink color change on papers with different surface properties

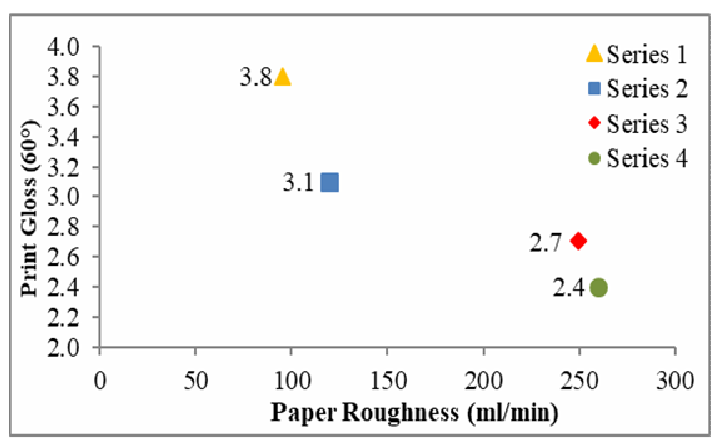

Figure 5: Relationship between paper roughness and print gloss

Table 2

Color change and light fastness sensitivity after ink withering test on different paper surfaces

\begin{tabular}{lcc}
\hline Paper type & $\Delta E^{*} a b$ & $\begin{array}{c}\text { Degree or } \\
\text { light fastness }\end{array}$ \\
\hline Series 1 & 4.71 & WS 4 \\
Series 2 & 5.85 & WS 3 \\
Series 3 & 4.75 & WS 4 \\
Series 4 & 8.37 & WS 3 \\
\hline
\end{tabular}

The most common form of calibration for light fastness testing is the blue wool (BW) scale. ${ }^{29}$ The light fastness standard consists of a graded set of blue colored wool in 8 light fastness steps, therefore referred to as the wool scale. The degrees of light fastness determined in this way are classified as follows: $1=$ very poor, $2=$ poor, $3=$ moderate, $4=$ fairly good, $5=\operatorname{good}, 6=$ very good, $7=$ excellent, $8=$ maximum.$^{30}$

In order to determine the effect of paper surfaces on the printing color fading behavior, printing samples were gradually withered using a Solarbox 1500 KFG-2400 Light Fastness Tester, with a xenon system. Measurements were made in accordance with British Standards (BS) 4321 and the results were evaluated according to the blue wool scale. The color change $\left(\Delta E^{*}{ }_{a b}\right)$ on the paper surfaces after the light fastness test was determined by calculating the difference between the color $L^{*} a^{*} b^{*}$ values measured with the spectrophotometer before and after fading.

After the fading test, differences in the printing colors on the test papers were detected (Table 2). The fact that the prints were made under the same environment conditions and using the same ink reveals that the color changes were caused by the paper characteristics. However, the fact that the color changes are not directly proportional to the surface roughness of the paper shows that other surface and structural properties of the paper can also be effective in the light fastness of the ink. Therefore, the effect of other surface and structural parameters of the paper on light fastness should be also investigated. 


\section{CONCLUSION}

It largely depends on the surface structure of the paper whether printing can be obtained without loss and at the desired color value. As surface roughness increases in test papers, the change in printed ink color has also increased over time. Therefore, considering that the color may change over time in multicolored prints, smoother papers with high wettability (low liquid contact angle) and surface energy should be preferred.

To obtain a homogeneous and glossy ink film on the paper surface, the film thickness of the ink must be greater than the roughness on the surface of the paper. However, increasing the ink film thickness adversely affects other print quality parameters and the ink takes longer to settle on the paper. Dot gain, color deviation, set-off and strike-through problems increase in printing. For these reasons, it is not a correct approach to increase the ink film thickness or ink density in printing works where high print gloss is desired. Instead, smooth surface papers should be preferred and the ideal print gloss should be achieved by printing at optimum ink density values. The study showed that there is a direct connection between the surface roughness of the paper and the print gloss. In test prints, higher printing brightness was obtained with low paper surface roughness. This result shows that the use of paper with low surface roughness is important in terms of enabling printability with lower solid ink density, reducing drying and printing problems.

Finally, this study showed that, in addition to the color pigment, paper as a printing substrate also had an effect on ink light fastness. Therefore, the printing substrate factor should also be considered in printing studies on light fastness sensitivity.

\section{REFERENCES}

1 B. Thompson, "Printing Materials, Science and Technology", $2^{\text {nd }}$ ed., U.K., Pira International, 2004, pp. 260-264

S. Sharma and D. Siginer, Appl. Mech. Rev. 63, 020802-1 (2010), https://doi.org/10.1115/1.4001047

3 M. Daun, PhD Thesis, Technischen Universitat Darmstadt, Deutschland, 2006, http://tuprints.ulb.tudarmstadt.de/epda/000760/M-Daun.pdf

4 C. Aydemir, S. Yenidoğan, A. Karademir and E. Arman, Mater. Manuf. Process., 32, 1310 (2017), https://doi.org/10.1080/10426914.2017.1279323
5 C. Aydemir, Z. Özomay, A. Karademir and E. A. Kandırmaz, Sci. Eng. Compos. Mater., 20, 141 (2013), https://doi.org/10.1515/secm-2012-0070

6 T. Cigula, T. Tomasegovic and T. Hudika, Nord. Pulp Pap. Res. J., 34, $540 \quad$ (2019), https://doi.org/10.1515/npprj-2019-0018

7 S. Yenidoğan, C. Aydemir, A. Karademir and E. A. Kandırmaz, Cellulose Chem. Technol., 53, 325 (2019), https://doi.org/10.35812/cellulosechemtechnol.2019.53 .32

8 J. E. Kasmani, S. Mahdavi, A. Alizadeh, M. Nemati and A. Samariha, Bioresources, 8, 3 (2013), https://doi.org/10.15376/biores.8.3.3646-3656

9 B. N. Altay, S. Bloembergen, C. Aydemir, A. Karademir and P. D. Fleming, J. Graph. Eng. Des., 8, 39 (2017), http://doi.org/10.24867/JGED-2017-1-039

10 C. Aydemir, S. Yenidoğan and S. A. Özsoy, Cellulose Chem. Technol., 54, 89 (2020), https://doi.org/10.35812/CelluloseChemTechnol.2020. 54.10

11 H. M. Koivula, PhD Thesis, ̊̊bo Akademi University, $\quad$ Turku, 2012, https://core.ac.uk/download/pdf/39944143.pdf

12 C. Aydemir, Sci. Eng. Compos. Mater., 23, 565 (2016), https://doi.org/10.1515/secm-2013-0266

13 H. Modaressi and G. Garnier, Langmuir, 18, 642 (2002), https://doi.org/10.1021/la0104931

${ }_{14}$ N. R. Tas, J. Haneveld, H. V. Jansen, M. Elwenspoek and A. van den Berg, Appl. Phys. Lett., 85, 3274 (2004), https://doi.org/10.1063/1.1804602

15 A. Marmur and R. D. Cohen, J. Colloid Interface Sci., $\quad$ 189, $299 \quad$ (1997), https://doi.org/10.1006/jcis.1997.4816

16 C. Aydemir, S. Yenidoğan, A. Karademir and E. A. Kandirmaz, J. Appl. Biomater. Funct., 16, 137 (2018), https://doi.org/10.1177/2280800018764761

17 T. Huhtamäki, X. Tian, J. T. Korhonen and R. H. A. Ras, Nature Protocols, 13, 1521 (2018), https://www.nature.com/articles/s41596-018-0003z.pdf?origin $=$ ppub

18 ASTM D5946-01, Standard Test Method for Corona-Treated Polymer Films Using Water Contact Angle Measurements, ASTM International, West Conshohocken, PA, 2001, www.astm.org

19 A. Rudawska and E. Jacniacka, Int. J. Adhes. Adhes., $\quad 29, \quad 451 \quad$ (2009), https://doi.org/10.1016/j.ijadhadh.2008.09.008

${ }^{20}$ R. W. G. Hunt, "The Reproduction of Colour", $6^{\text {th }}$ ed., England, John Wiley \& Sons Ltd., 2004, pp. 126138

${ }^{21}$ N. Kašiković, D. Novaković, N. Milić, G. Vladić, Ž. Zeljković et al., Teh. Vjesn., 22, 33 (2015), https://doi.org/10.17559/TV-20130928115500

22 P. Nussbaum, PhD Thesis, The Norwegian Color Research Laboratory Faculty of Computer Science and Media Technology Gjovik University College, Norway, 2010, file://C:/Users/MARMARA/Downloads/PhD\%20Thes is-Peter\%20(5).pdf 
23 C. Horvath and P. G. Tóth, in Procs. $9^{\text {th }}$ International Symposium on Graphic Engineering and Design Conference, Novi Sad, Serbia, November 0810, 2018, pp. 323-332, https://doi.org/10.24867/GRID2018-p39

24 C. Aydemir, A. Karademir, S. İmamoğlu, B. N. Altay, P. D. Fleming et al., Cellulose Chem. Technol., 53, 787 (2019), https://doi.org/10.35812/CelluloseChemTechnol.2019. 53.77

25 W. S. Mokrzycki and M. Tatol, Mach. Graph. Vis., 20, 383 (2011), https://dl.acm.org/doi/abs/10.5555/3166160.3166161 26 A. Ashori and W. D. Raverty, Polym. Plast. Technol. Eng., 46, 683 (2007), https://doi.org/10.1080/03602550701429250
27 C. Aydemir and C. Özakhun, "Matbaa Malzeme Bilimi”, Marmara University Publication, 2014, pp. 248-252, http://bt.ubyo.marmara.edu.tr/en/ourpublished-books/

28 N. Narakornpijit, Master's Thesis, Rochester Institute of Technology, New York, 2018, https://scholarworks.rit.edu/cgi/viewcontent.cgi?article $=10977 \&$ context $=$ theses

29 S. L. Pugh and J. T. Guthrie, Color. Technol., 31, $42 \quad$ (2001), https://doi.org/10.1111/j.14784408.2001.tb00137.x

30 C. Aydemir and S. Yenidoğan, J. Graph. Eng. Des., 9, 37 (2018), http://doi.org/10.24867/JGED2018-1-037 